\title{
Smart City EU - Lighthouse Projects - Investigation of Economic Benefits
}

\begin{abstract}
Aik Wirsbinna
Faculty of Business and Economics, Mendel University in Brno, Czech Republic
\end{abstract}

\begin{abstract}
The major European Smart City Lighthouse Projects have gained a lot of attention and importance from the designers of Smart City Initiatives (SCI) since 2014. The EU Commission's funding under the Horizon 2020 program is significant. The supported cities include the European metropolises but also several smaller cities. All these cities are repeatedly named Smart City pioneers. However, the research still has a gap when it comes to value generation. This article deals with the economic benefits of these Lighthouse projects. The own developed categories are applied and proved with Lighthouse projects. The range of economic benefits is shown and evaluated using the qualitative content analysis of the data from the EU - CORDIS database. The sustainability in the Smart City Initiatives is showcased as economic benefit is prioritized higher than cost saving or efficiency.
\end{abstract}

Keywords: smart city, economic benefits, urban studies, sustainability, lighthouse projects, EU - Programs

\section{Introduction}

The global trend of an increasingly urban population is regularly mentioned as a trigger for Smart City thoughts. The figures and statistics have to date additionally spoken truely. Already, more than $50 \%$ of the world's population lives in cities (United Nations, 2019) and growth is expected to continue. The development can be seen not only in the populous countries of Asia but also in Europe as shows the development in Germany or Western Europe in general. The reasons for this are manifold: Significantly better living conditions, job opportunities, education and culture are mentioned by a multitude of researchers such as Henderson (2010), Brenner (2013) or Wang et al. (2012).

This increasing urbanization contributes to the economic and social importance of cities, but also to their poor environmental sustainability (Shen, Peng, Zhang, \& Wu, 2012). Recognition of this trend is driving studies into new ways of adapting to rising requests and urgent problems; e.g. physical risks, such as the deterioration of 
conditions in air and transport, and economic risks such as unemployment (Albino, Berardi, \& Dangelico, 2015). The Smart City is a new manner of looking at cities. The optimization of available and new resources and possible investments are required (Lazaroiu \& Roscia, 2012). The present paper seeks to address the concept of smart cities as a contemporary way to approach the challenges arising not only from the ongoing urbanization trend but also from overall societal trends such as increased digitalization of daily life (Parviainen, Tihinen, Kääriäinen, \& Teppola, 2017) or the demand for more sustainable solutions - not only, but also within the concept of urban development (Bibri, 2018).

\section{The concept of the Smart City}

Smart Cities use technologies, including Information Communication Technology (ICT), to enable more efficient provision of services (Albino et al., 2015). Especially within the time of the Covid 19 pandemic period, the large need for facts, data and information of the population, which is mainly economically present in urban areas, is evident (Wirsbinna, 2021). The publications, therefore, show an increasing interest in transforming the physical environment and performance of a city into a digital level (Lyons, Mokhtarian, Dijst, \& Böcker, 2018). While the Covid 19 crisis has accelerated this trend (see Cheshmehzangi, 2021), the trend towards more increased and innovative concepts for city development is an already on-going one, as De Dutta and Prasad (2020) or Balogun et al., (2020) explain. The Smart City approach, which is among the most outstanding concepts in addressing these changes, has a wide range of sub-research areas. In this paper, I focus on the necessary basics to answer the research question, how the economic benefits of Smart Cities can be evaluated. In order to approach this question, an overview of relevant results regarding Smart Cities, their value creation and their benefits is presented before the empirical work shifts its focus onto European Union's Lighthouse Projects.

\section{Smart City Definition}

There are many different smart city definitions in the research literature and no uniform picture has yet emerged. Depending on the perspective of a city and its framework, the concept of Smart City encompasses the meaning of the word "intelligent": Smart City, knowledge city, ubiquitous city, sustainable city, digital city, etc. but no defintion has been universally recognized (Paola \& Rosenthal-Sabroux, 2014). The research published a few definitions. Especially in the recent period, many scientific papers have been published, many of them not older than 10 years, which deal with the subject (Albino et al., 2015). Ruhlandt (2018) has conducted a systematic method according to the Webster and Watson (2002) review standard to cluster the different definitions and studies. The picture remains confused as to how the concept of a Smart City can be considered (Wirsbinna, 2021). Different approaches are used, but their differences are not clearly articulated or delimited either (Townsend, 2017). 
The different approaches in the Smart City Definition can be summarized as follows:

The technology approach of a Smart City strongly links "smart" with applications of ICT. A smart city [...] is one that capitalizes on the opportunities presented by ICT in promoting its prosperity (Odendaal, 2003). „The use of smart computing technologies to make the critical infrastructure components and services of city-which include city administration, education, healthcare, public safety, real estate, transportation, and utilities- more intelligent, interconnected, and efficient" (Washburn et al., 2010, P. 2).

The governance-focused approach focuses on the "smart" interaction of many actors but also on the possibility of differentiating themselves from other groups (Wirsbinna, 2020). Smart City as a strategic urban orientation, while networking with governance is of a certain importance. „We believe a smart city to be smart when investments in human and social capital and traditional (transport) and modern (ICT) communication infrastructure fuel sustainable economic growth and a high quality of life, with a wise management of natural resources, through participatory governance.“ (Caragliu, A., Del Bo, C., \& Nijkamp, 2011, P.6) or „Academic literature highlights governance-related elements of smart cities. It suggests particularly three elements: (1) e-governance, (2) engagement by stakeholders, citizens and communities, and (3) network-based relationships such as partnerships and collaborations." (Gil-Garcia, Pardo, \& Nam, 2015, P. 69)

Much of the definitions in the literature try to describe the multidimensionality and complexity of different areas of a city in a community approach (Wirsbinna, 2021). Giffinger et al. (2007) identified the area's economy, people, governance, mobility, environment, and living identifiers, which are combined with each other in a Smart City. „A smart city is a city well performing in a forward-looking way in six "smart" characteristics, built on the "smart" combination of endowments and activities of selfdecisive, independent and aware citizens" (Giffinger et al., 2007, P.10-11).

The importance of the Smart City approaches and the high number of publications, further systematic literature analysis and reviews are available on the various Smart City definitions (see Ismagilova, Hughes, Dwivedi, \& Raman, 2019; Moustaka, Vakali, \& Anthopoulos, 2019; Ruhlandt, 2018; Zheng, Yuan, Zhu, Zhang, \& Shao, 2020).

The different definitions of Smart City in the past mostly focus on the role of communication infrastructure. However, this principal aim reflects the demands from the period from the beginning of 1990 to 2000, when the Smart City label first gained interest when the ICT first reached a wide audience in European Countries (Caragliu, A., Del Bo, C., \& Nijkamp, 2011). The development of the internet and digital reality plays a major role in the urban development. The combination of hard factors such as the use of ICT has increasingly been complemented by soft factors. The dimensions developed by Giffinger et al. (2007) take this up and this is reflected today in most concepts of smart cities as well as in EU projects. 
Nevertheless, the question remains, why the Smart City concept remains elusive. This question is related on the one hand to the complexity of the urban processes and on the other hand, the factors mentioned by Giffinger et al. (2007) were already existing before the Smart City approach came up. This raises the question about the novelty of the concept.

It is the reduction of these factors with the new and higher performant digitization. The technological possibilities and the networking have increased massively in this context. In addition to the development of the digital space through social media, it is also increasingly a driving force behind further development of the concept of a city (Wirsbinna, 2021). The connection and interaction resulting from these contemporary developments lead to a Smart City transformation (Molinillo, AnayaSánchez, Morrison, \& Coca-Stefaniak, 2019). Social reality describes all people and behaviour in a city. The urban reality describes all the buildings, streets, and infrastructures of a city. This refers to the physical level of a city. Social reality and urban reality are the traditional city in this context (See Erokhina, Mukhametov, \& Sheremetiev, 2019). Social reality shapes urban reality through the decisions. But now, the new digital reality is added. The engagement of social reality with digital reality is now well recognized. Social media, e-commerce, mobile devices are now indispensable in our everyday lives and continue to grow (Okhrimenko, Sovik, 2019). The connection of urban reality with digital reality is not fully developed yet. The first implementations have, of course, already been made here. But if one looks at the factors of Giffinger's Smart City (Giffinger et al., 2017), it becomes evident that digitization is not connected to all factors. At this point, the development path to a uniform view of a Smart City is not described fully yet.

\section{Value creation of Smart City Initiatives (SCI)}

Smart cities are associated with high investments, they usually concern innovation development, and infrastructure, require careful planning and political support (Anthopoulos, Fitsilis, \& Ziozias, 2016). The question of economic impact is therefore very justified. A study prepared by Capgemini Invent (European Commission, 2020j) as part of the European Data Portal examines the economic impact of open data. Here, the question of the impact of freely accessible data plays a particular role (European Commission, 2020j). "Several benefits of using Open Data have been identified and consist of direct and indirect benefits. Direct advantages are realized in market transactions in the form of turnover and gross value added, the number of jobs associated with the production of a service or product, and cost savings. Indirect economic benefits include new goods and services, time savings for users of open data applications, growth of the knowledge-based economy, increased efficiency in public services and growth of related markets" (Wirsbinna 2021, P.34-36). According to this publication, the market size of Open Data is expected €199.51 - €334.20 billion forecast for 2025. The projected numbers of direct open data jobs are $1.12-1.97$ 
million employees forecast for 2025 . The projected cost savings of the public sector for the EU28 + in 2020 will be €1.1 billion. Efficiency gains are measured in a qualitative approach (European Commission, 2020j).

\section{Economic Benefits of Smart City Initiatives (SCI) - a category approach}

In the literature, there are a number of descriptions that indicate an economic benefit of SCI (Wirsbinna, 2021) with positive effects. However, no definitive answer can be derived in regard to the exact benefit. A generally valid proof could not be provided yet. A first classification by possible categories (Table 1) has been developed by Wirsbinna (2021). The category formation helps to evaluate the different economic benefits.

Table 1: Categories of economic benefit of SCI

\begin{tabular}{|l|l|}
\hline$№$. & Categories of economic benefit of SCI \\
\hline 1 & Efficiency \\
\hline 2 & Cost savings \\
\hline 3 & Security \\
\hline 4 & City attractiveness \\
\hline 5 & Connectivity \\
\hline 6 & Sustainability \\
\hline 7 & Smart Transportation \\
\hline 8 & Smart Buildings \\
\hline 9 & Funding \\
\hline
\end{tabular}

Source: (Wirsbinna, 2021), Page 38

EU - Lighthouse Projects

The European Commission has funded the Lighthouse projects for smart cities and municipalities under the Horizon 2020 research and innovation program. The SCIs are designed to develop solutions and business models that can be scaled and replicated, leading to measurable benefits for cities (European Commission, 2020i). Many well-known SCIs have received their initiation from the EU-Lighthouse Project. For example, Barcelona became one of the leading European cities in the Smart City sector with the "GROWSMARTER" Program. Since 2014, a total of 17 projects (Table 2 ) have been financed. All projects are driven by the same challenges facing EU cities. The total EU funding currently amounts to $€ 360$ million in a period from 2015 to 2024 (European Commission, 2020i). The aim is to ensure the economic viability as well as the efficiency in other cities. These projects include lighthouse cities and a number of follower cities working together to demonstrate these processes, technologies and business models and transform their ecosystems into smarter and more sustainable 
places (European Commission, 2016). Lighthouse cities are also called city pilots because they carry out the SCI first and then other cities can learn from the experiences to generate success in the "follower cities" more efficiently. To this end, conferences are regularly organized by the EU and contributions are shared (European Commission, 2020i). Public money funding also forces a review and progress report to the European Commission. The Community Research and Development Information Service (CORDIS) is the European Commission's primary source of results from the projects funded by the EU's framework programmers for research and innovation (European Commision, 2020). CORDIS maintains a structured public database of all European Commission project information, such as project fact sheets, participants, reports, results, and links to freely accessible publications.

Table 2: List of EU - Lighthouse Projects

\begin{tabular}{|c|c|c|c|c|}
\hline Project №. & EU-Lighthouse Projects & Pilot Cities (Lighthouse Cities) & Timeline & $\begin{array}{l}\text { Budgets - EU } \\
\text { Contributions ( } € \\
\text { million) }\end{array}$ \\
\hline 1 & SPARCS & ESPOO, Leipzig & 2019 to 2024 & 19,7 \\
\hline 2 & POCITYF & Evora, Alkmaar & 2019 to 2024 & 19,9 \\
\hline 3 & ATELIER & Bilbao, Amsterdam & 2019 to 2024 & 19,6 \\
\hline 4 & CITYXCHANGE & Limerick, Trondheim & 2018 to 2023 & 19,9 \\
\hline 5 & MAKING-CITY & Oulu, Groningen & 2018 to 2023 & 18,1 \\
\hline 6 & STARDUST & Tampere, Trento, Pamplona & 2017 to 2022 & 17,9 \\
\hline 7 & MATCHUP & Dresden, Valencia, Antalya & 2017 to 2022 & 17,4 \\
\hline 8 & IRIS & Cute, Gothenburg, Utrecht & 2017 to 2022 & 17,9 \\
\hline 9 & RUGGEDISED & Umea, Rotterdam, Glasgow & 2017 to 2021 & 17,6 \\
\hline 10 & MYSMARTLIFE & Helsinki, Nates, Hamburg & 2016 to 2021 & 18,6 \\
\hline 11 & SMARTER TOGETHER & Vienna, Lyon, Munich & 2016 to 2021 & 24,7 \\
\hline 12 & SMARTENCITY & $\begin{array}{l}\text { Sonderborg, Tartu, Vitoria- } \\
\text { Gasteiz }\end{array}$ & 2016 to 2021 & 27,8 \\
\hline 13 & SHARINGCITIES & Milano, Lisbon, London & 2016 to 2020 & 24,7 \\
\hline 14 & REPLICATE & $\begin{array}{l}\text { Florence, San Sebastian, } \\
\text { Bristol }\end{array}$ & 2016 to 2021 & 24,9 \\
\hline 15 & TRIANGULUM & $\begin{array}{l}\text { Stavanger, Eindhoven, } \\
\text { Manchaster }\end{array}$ & 2015 to 2020 & 24,4 \\
\hline 16 & REMOURBAN & $\begin{array}{l}\text { Valladolid, Tepebasi, } \\
\text { Nottingham }\end{array}$ & 2015 to 2019 & 21,5 \\
\hline 17 & GROWSMARTER & $\begin{array}{l}\text { Cologne, Barcelona, } \\
\text { Stockholm }\end{array}$ & 2015 to 2019 & 24,8 \\
\hline
\end{tabular}

Source : https://eu-smartcities.eu/ 
The different SCI of the Lighthouse Projects pursue different objectives. It is now analyzed which economic benefits can be filtered out of the projects These can be clustered qualitatively.

Research question (RQ): In terms of Smart City Lighthouse Projects, which economic benefits can be evaluated?

Therefore, this research question builds on the research presented above and aims to provide a more systematic and structured understanding of the problem at hand. By focusing on comparable projects (see section 2), such an endeavor becomes possible.

\section{Methodology and Data}

In order to answer the question, where the economic benefits of SCI of EU - Lighthouse Projects are, a further intensive analysis is necessary. To answer the proposed research question, an extensive review of Community Research and Development Information Service (CORDIS) Project descriptions and a qualitative content analysis was performed (Mayring, 2010). CORDIS publishes all the objectives and (partial) results of the EU - Lighthouse Projects. Publications are available in the database in a standardized manner and are regularly updated to show the commission's progress (European Commission, 2021). This material was analyzed using the qualitative content analysis according to Mayring (Mayring, 2010). For further investigation about CORDIS pages with 17 lighthouse projects were encoded with the help of software (Table 3). The software MAXQDA (Kuckartz, 2016) was used to analyze the given information. The code system follows the deductive category formation, which represents the economic benefits (see Table 1) (Wirsbinna, 2021).

Table 3: MAXQDA Project Information

\begin{tabular}{|l|}
\hline EU-Lighthouse projects - MAXQDA \\
\hline Document groups: 17 (Lighthouse projects) \\
\hline PDF documents: 38 (CORDIS) \\
\hline Codes: 47 \\
\hline Encoded segments: 160 \\
\hline
\end{tabular}

Scource : own Table 


\section{Results}

The evaluation of the economic needs of EU-Lighthouse Project shows that all categories are affected. The frequency distribution gives the following picture, see Figure 3. Therein, it becomes visible that the topic of sustainability - as discussed within the introduction of this paper - is considered among the most crucial aspects of outcomes alongside outcomes related to smart transportation and smart buildings.

Figure 2: Distribution of Economic Benefits of EU - Lighthouse Projects (own Figure)

Source: (own Figure)

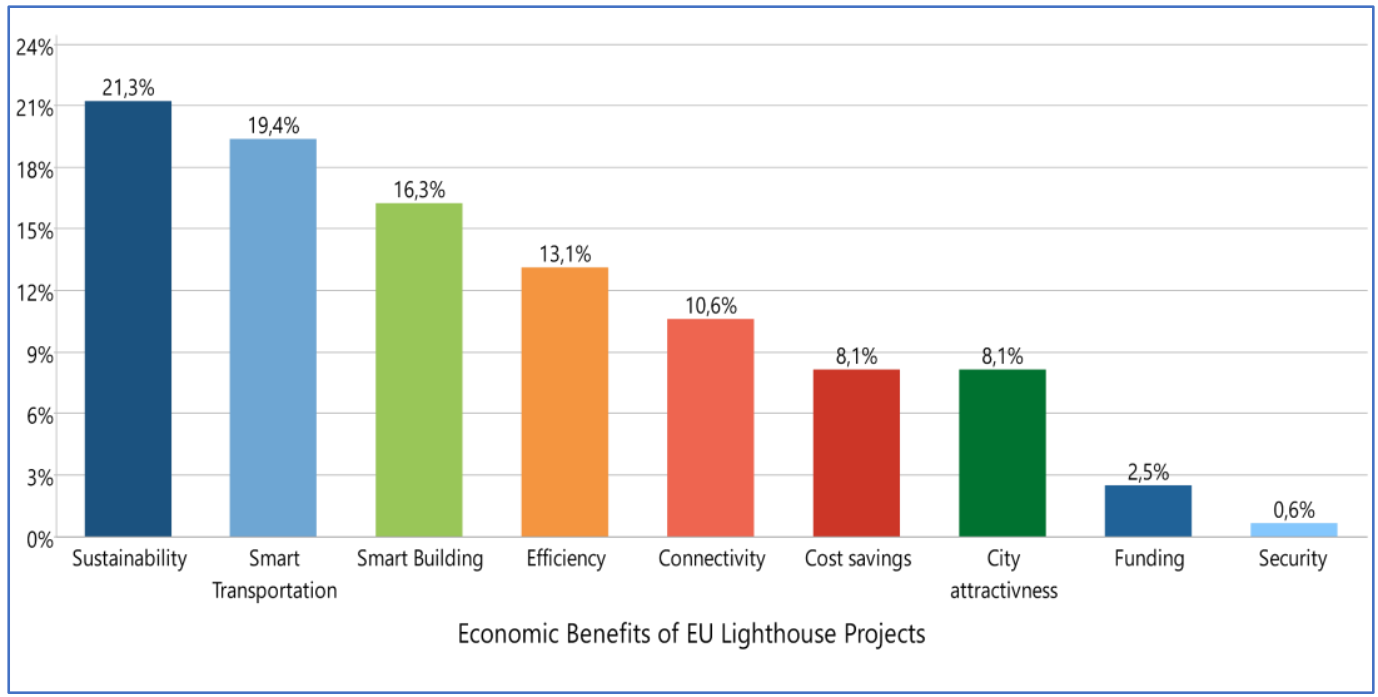

Security-related issues are only considered to be a minor aspect of the EU Lighthouse projects, which also seems true for the funding aspect. Improving the overall city attractiveness and leading to cost savings are also comparatively rarely mentioned among the economic benefits of Smart City projects.

The 17 Lighthouse Project is particularly focused on sustainable economic benefits. These have been mentioned most frequently. The least mention has been made of security issues Figure 4 shows the distribution of codes between categories. 
Figure 3: Code Relation Bowser

\begin{tabular}{|c|c|c|c|c|c|c|c|c|c|c|c|c|c|c|c|c|c|c|c|c|}
\hline Codes & Project No. & 1 & 2 & 3 & & 4 & 5 & 6 & 7 & 8 & 9 & & 10 & 11 & 12 & 13 & 14 & 15 & 16 & 17 \\
\hline$>$ City attractivness & & $\bullet$ & $\bullet$ & & & & O & $\bullet$ & O & & $\bullet$ & & $\bullet$ & $\bullet$ & $\bullet$ & & & & & 0 \\
\hline$>$ Connectivity & & & & & & 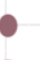 & & & O & & 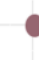 & & $\bullet$ & & & & $\bullet$ & & 0 & \\
\hline$>$ Cost savings & & & & & & 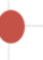 & & & $\bullet$ & & $\bullet$ & & & & & $\bullet$ & $\bullet$ & & - & \\
\hline$>$ efficiency & & • & $\bullet$ & & & $\bullet$ & & $\bullet$ & $\bullet$ & $\bullet$ & $\bullet$ & & & & $\bullet$ & $\bullet$ & $\bullet$ & & $\bullet$ & \\
\hline$>$ ๑Funding & & & $\bullet$ & & & - & & & & & & & & & & & & & & \\
\hline$>$ Security & & & & & & & & & & & & & & & & & & & & \\
\hline$>$ Smart Building & & - & 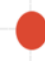 & & & 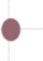 & & & - & & & & & $\bullet$ & $\bullet$ & & $\bullet$ & 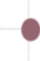 & & \\
\hline$>\ominus_{0}$ Smart Transportation & & & - & & & , & & & - & & & & & - & $\bullet$ & & & & $\bullet$ & \\
\hline$>$ Sustainability & & & & & & 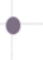 & & & & & & & & $\bullet$ & $\bullet$ & & - & & $\bullet$ & \\
\hline$\sum$ SUMME & & & 14 & & & 15 & 6 & 4 & 14 & 4 & I & & 5 & 6 & 7 & 3 & 6 & & 11 & \\
\hline
\end{tabular}

Source: (own Figure)

\section{SCI Benefits - Efficiency}

Improving efficiency rates is also an issue for the EU - Lighthouse Projects. However, the majority of these relate to the reduction of energy consumption or the modernisation of installations. The CITYXCHANGE project states: "+CityxChange will create solutions for Positive Energy Blocks leading to Positive Energy Districts and Cities through (i) decision support tools that enable informed decisions to be made by all stakeholders in the community, (ii) an approach to creating a positive energy block through energy reduction and efficiency measures, local renewable, local storage, flexibility and peer-to-peer energy trading and (iii) top-down community engagement driven by the local authority and bottom-up citizen engagement to inform, educate and drive behavioural change." (European Commission, 2018a) or in the Project RUGGEDISED: "It will showcase economic viability to significantly increase cities' overall energy and resource efficiency through actions addressing the energy systems, mobility, climate change, water and air quality." (European Commission, 2020e). Efficiency can also be improved by new technologies. Here, too, there is a scope of the GROWSMARTER from the project of the Smart City of Barcelona: "... The Smart Tower solution provides new telecommunication micro sites and sensors. The API implemented for the Smart Lighting System communicates with other applications. The Multiservice Concentrator collects and uploads data from utility meters and sensors to the data platform, which can improve resource utilization. " (European Commission, 2019). 


\section{SCI Benefits- Cost Savings}

The coding of "Cost Savings" has shown that the projects are mainly working towards energy consumption and resource conservation, too. As the Lighthouse project MATCHUP describes: "This program is a resource-saving measure that promotes an innovative business model: saving energy and costs in schools." (European Commission, 2020b).

Not all projects have references to the subcategories within the main category I developed. However, the CITYXCHANGE project states: "IoT a technology enables energy meters to automatically communicate with each other and exchange important information. Energy can be requested and offered decentral. All operations are processed via the Tangle, so that the market functions completely decentralized and without intermediaries." This system allows facilities in cities such as solar roofs, buildings, electric vehicles and batteries to track electricity in real time and thus act to decentralise and cost-effectively generate electricity supply and demand through a power exchange network (European Commission, 2018a) In the field of digitalization, companies with experience in this area are working together in the same practice. This is based on lower transaction costs.

\section{SCI Benefits- Security}

The SCI is the weakest in the area of security. This factor was mentioned only once in the area. The company IBM and the City of Stockholm have tested a camera - based security system in the project GROWSMARTER "The installation of Internet of Everything in an event arena provides added value for lighting, parking, transport, and maintenance. IBM and the City of Stockholm are testing a secure process of gathering camera-based" (European Commission, 2019). In all other projects, this economic benefit to avoid risk and damages played a negligible role.

\section{SCI Benefits- City Attractiveness}

The topic of city attractiveness is mentioned again and again in the SCI. There are goals such as "citizen oriented" in STARDUST (European Commission, 2020g)"direct engagement of citizens" in MATCHUP (European Commission, 2020b) "societies that improve citizens" quality of life, create jobs and wealth, and offer equal growth of opportunities" in SMARTENCITY project (European Commission, 2018c). Four illuminated projects promise approximately 9.000 new jobs in the target descriptions and thus clearly show economic advantages. The latest Lighthouse Project SPARC combines economic growth and quality of life as a benefit, "The impacts include economic growth, improving the quality of life and environmental benefits in relation to the EC's climate and energy policy framework. SPARCS co-creation brings together citizens, businesses, research institutions, urban planning and decision-making bodies and transforms cities into carbon-free inclusive communities (European Commission, 2020f). 


\section{SCI Benefits- Connectivity}

In the field of connectivity, the focus is on big data and IoT. "... the development of city 3D models and the stimulate city of the demand side in the next 10 to 20 years..." in the MYSMARTERLIFE shows that with the help of big data information storage, new services will be offered in the future (European Commission, 2020c). At the same time, IoT is intended to build so-called Urban Data Platforms (UDPs). "These enable digital technologies to integrate data flows via open standards within and across city systems used by both the public and private sector. For example, platforms can share raw data streams or show 3D visualizations of how underground piping, bus lines, thermal grids, environmental data and a wide range of other information are connected"; RUGGEDISED (European Commission, 2020e).

\section{SCI Benefits- Sustainability}

In code distribution (see introduction to section 3), the benefit of sustainability has been mentioned most often. The Lighthouse Project POCITYF gives sustainability the highest priority: "Against this backdrop, air quality is expected to worsen due to inefficient buildings and $\mathrm{CO} 2$ emissions from transport. Therefore, transforming cities into more sustainable and liveable places has become a priority. "(European Commission, 2020d). However, sustainability is seen in the iron cases in the sense of a $\mathrm{CO} 2$ reduction. The ATELIER project sets out concrete targets for measurability: "The EU-funded ATELIER project will demonstrate positive energy districts (PEDs) in eight European cities that will be for strive for sustainability and carbon neutrality. Amsterdam and Bilbao are two lighthouse cities that have committed to generating an energy surplus of $1340 \mathrm{MWh}$ of primary energy, prevent $1.7 \mathrm{kt}$ of CO2 and $23 \mathrm{t}$ of NOx emissions, and invest EUR 156 million to realise their PED goals. Bratislava, Budapest, Copenhagen, Krakow, Matosinhos, and Riga are the fellow cities that will replicate and adapt successful solutions. " (European Commission, 2020a).

\section{SCI Benefits-Smart Transportation}

In the area of smart transportation, the focus is on electromobility and the associated expansion of the infrastructure. The first projects in 2015 have already started the topic. In Eindhoven, for example, TRIANGULUM installed 14 electric vehicle charging stations. Concrete figures are often mentioned in these project to increase the use of electric vehicles and charging infrastructure $(100 \%$ in Eindhoven and Manchester as from 2014) (European Commission, 2020h), with the aim with its merit of innovation offers the integration of e-mobility to as well promote the decarbonisation of the mobility sector. In RUGGEDISED it was clearly formulated: "...increasing the use of electric vehicles to improve air quality and reduce $\mathrm{CO} 2$ emissions" (European Commission, 2020e). A concrete benefit is described again in GROWSMARTER: "... Smart taxi stands have helped increase the use of parking stations and reduce the empty cruising for clients. Fast electric vehicles charging stations have been installed. ..." (European Commission, 2019). 


\section{SCI Benefits- Smart Building}

Smart Building Initiatives are present in almost all projects. Energy-related considerations also play a major role in the overall development approaches. The development of districts or boroughs that consume less energy or can produce more than they consume using renewable energy - thus so-called positive energy districts (PED) - were often called initiatives to generate an economic advantage. This includes the retrofitting of buildings. But also, the smart connection within a quartier should generate corresponding benefits. For example, smart quartiers will be built in the Lighthouse Cities Evora (Portugal), Alkmaar (Netherlands): "The two Lighthouse cities will benefit from solutions divided into four "Energy Transition Tracks": Innovative solutions for positive buildings and districts, peer to peer energy management and storage solutions for grid flexibility, e-mobility integration into smart grid and city planning and citizen-driven innovation in co-creating Smart City solutions." (European Commission, 2020d). The smart home in the private sector, often mentioned in the Smart City Context, is not a big issue at the Lighthouse project. Only in the project TRINAGULUM one refers to a kind of renovation platform and was therefore interpreted into this correction: "... have made use of the digital renovation platform Woo connect and 174 made a plan/scenario for the renovation of their home. The Eindhoven open data platform has been visited 96.000 and downloaded 4.000..."(European Commission, 2020h)

\section{SCI Benefits- Funding}

The EU finances a large part of the Lighthouse projects, as the analysis implied. In doing so, the EU aims to promote innovations that have a high potential for future market readiness. CITYXCHANGE states: "This initiative identifies innovations and innovators with high potential for EU-funded framework programmes for research and innovation and assesses their market maturity." (European Commission, 2018b). However, funding aspects are not mentioned outside of this statement.

\section{Discussion and Conclusions}

\section{Main Contribution}

The economic benefits and value generation can be very diverse in Smart City. This is not surprising since smart cities are a broad concept. The study of the 17 Smart City Lighthouse Projects with the help of the qualitative content analysis has shown that only a narrow range of benefits are generated here. The focus is on sustainability in the broader sense and $\mathrm{CO} 2$ reduction and energy savings in the narrower sense. The energy system and the electricity distribution are high on the agenda too. Obviously, the EU see the greatest potential to generate a Smart City. The economic benefits related to ICT or IoT are low. It was actually expected that the Smart City strategies would also focus on these benefits, as there is a great potential in the form of economic benefits. It seems that the EU's guidelines are very narrow here and that the 
framework does not allow it. The idea that follows is that the EU equates a Smart City with a sustainable city. None of the projects have brought the issue of e-government, which seems to be a national task from the EU's point of view. Here, too, the potential that could make administration more efficient in individual cities is missed. It is also critical to note that the EU documents and descriptions examined have remained very abstract. It is to be assumed, however, that the picture would not have changed significantly. It remains to be seen whether the economic benefits described have also been lifted. Here, too, the EU has developed as a control a complex reporting tool, which reports even more detail on progress. Expert interviews could also help to gain further insights regarding the economic benefits of SCI. Experts are associated with the direct implementation of the SCI, so they have more knowledge about the effectiveness of measures and their benefits.

\section{Critical Discussion, Limitations \& Outlook}

The results presented throughout this paper directly refer to a specific group of projects - those connected to and funded by programs of the European Union. Thus, the results derived from this analysis have to be viewed through the lens of this general restriction, acknowledging that these Lighthouse projects - as the name already implies - do not necessarily yield effects comparable to those of less prominently developed projects. However, for the sake of the present analysis, such a restriction was necessary, as a broader lens of analysis might have led to stronger possibilities of generalization, while sacrificing the high level of internal validity and reliability obtained from the systematic approach utilized here.

It could further be shown that the topic of sustainability is indeed among the core considerations of the development of the Smart Cities referred to within this paper. This implies that the focus on greener and more sustainable cities, described by authors such as Paola and Rosenthal-Sabroux (2014) or Yigitcanlar and Kamruzzaman (2018), seems to be implemented strongly within the projects assessed throughout this paper. However, while this finding aligns with the overall expectations, it is recommended to consider them as a foundation for subsequent empirical work on the topic for future research. The results found here are based on descriptions of - outstanding - projects within the European Union. In order to present a more holistic assessment, additional resources will be necessary to showcase how far the development goals and the proclaimed benefits mentioned throughout these project descriptions are met in reality. This seems especially relevant towards the field of sustainability, thus to the most-often mentioned development goal of Smart Cities. By applying quantitative measures, (see Bell \& Morse, 2012), future research on these projects should aim to assess how far the goals are met and whether the benefits of Smart Cities can be brought to their optimal reality. 


\section{References}

[1] Albino, V., Berardi, U., \& Dangelico, R. M. (2015). Smart cities: definitions, dimensions, and performance. Journal in Urban Technology,. https://doi.org/10.1080/10630732.2014.942092.

[2] Angelidou, M. (2017). The Role of Smart City Characteristics in the Plans of Fifteen Cities. Journal of Urban Technology, 24(4), 3-28. https://doi.org/10.1080/10630732.2017.1348880

[3] Anthopoulos, L., Fitsilis, P., \& Ziozias, C. (2016). What is the source of smart city value? A business model analysis. International Journal of Electronic Government Research, 12(2), 56-76. https://doi.org/10.4018/IJEGR.2016040104

[4] Balogun, A. L., Marks, D., Sharma, R., Shekhar, H., Balmes, C., Maheng, D., ... Salehi, P. (2020). Assessing the Potentials of Digitalization as a Tool for Climate Change Adaptation and Sustainable Development in Urban Centres. Sustainable Cities and Society, 53, 101888. https://doi.org/10.1016/j.scs.2019.101888

[5] Bell, S., \& Morse, S. (2012). Sustainability indicators: Measuring the immeasurable? Second edition. In Sustainability Indicators: Measuring the Immeasurable? Second Edition. https://doi.org/10.4324/9781849772723

[6] Bibri, S. E. (2018). A foundational framework for smart sustainable city development: Theoretical, disciplinary, and discursive dimensions and their synergies. Sustainable Cities and Society, 38, 758-794. https://doi.org/10.1016/j.scs.2017.12.032

[7] Brenner, N. (2013). Theses on urbanization. Public Culture, 25(1), 85-114. https://doi.org/10.1215/08992363-1890477

[8] Caragliu, A., Del Bo, C., \& Nijkamp, P. (2011). Smart cities in Europe. Journal of Urban Technology, 65-82. https://doi.org/10.1080/10630732.2011.601117

[9] Cheshmehzangi, A. (2021). From Transitions to Transformation: A Brief Review of the Potential Impacts of COVID-19 on Boosting Digitization, Digitalization, and Systems Thinking in the Built Environment. Journal of Building Construction and Planning Research, 09(01), 26-39. https://doi.org/10.4236/jbcpr.2021.91003

[10] De Dutta, S., \& Prasad, R. (2020). Digitalization of Global Cities and the Smart Grid. Wireless Personal Communications, 113(3), 1385-1395. https://doi.org/10.1007/s11277-020-07478-w

[11] Erokhina, O. V., Mukhametov, D. R., \& Sheremetiev, A. V. (2019). New Social Reality: Digital Society and Smart City. 2019 Wave Electronics and Its Application in Information and Telecommunication Systems, WECONF 2019. https://doi.org/10.1109/WECONF.2019.8840644 
[12] European Commision. (2020). CORDIS. Retrieved December 27, 2020, from CORDIS DATABASE website: https://cordis.europa.eu/en

[13] European Commission. (2016). The Marketplace of the European Innovation Partnership on Smart Cities and Communities (EIP-SCC). Retrieved September 20, 2020, from Website website: https://eu-smartcities.eu/

[14] European Commission. (2018a). Horizion 2020 CITYXCHANGE Project 824260. Retrieved from CORDIS DATABASE website: https://cordis.europa.eu/project/id/824260

[15] European Commission. (2018b). Horizion 2020 CITYXCHANGE Project 824260. Retrieved from CORDIS DATABASE website: https://cordis.europa.eu/project/id/824260

[16] European Commission. (2018c). Horizon 2020 SMARTENCITY Project Nr. 691883. CORDIS DATABASE, $1-13$. Retrieved from https://cordis.europa.eu/project/id/691883

[17] European Commission. (2019). Horizon 2020 GROWSMARTER Project 646456. Retrieved from CORDIS DATABASE website: https://cordis.europa.eu/project/id/646456

[18] European Commission. (2020a). Horizon 2020 ATELIER Project Nr.411499. Retrieved from CORDIS DATABASE website: https://cordis.europa.eu/article/id/411499-atelier-smart-city-project-toturn-amsterdam-and-bilbao-into-citizen-driven-positive-energy-d

[19] European Commission. (2020b). Horizon 2020 MATCHUP Project Nr. 406957. Retrieved from CORDIS DATABASE website: https://cordis.europa.eu/article/id/406957-turning-problems-intoopportunities-in-urban-areas/en

[20] European Commission. (2020c). Horizon 2020 MYSMARTERLIFE Project Nr. 731297. Retrieved from CORDIS DATABASE website: https://cordis.europa.eu/project/id/731297

[21] European Commission. (2020d). Horizon 2020 POCITYF Project Nr. 410201. Retrieved from CORDIS DATABASE website: https://cordis.europa.eu/article/id/410201-pocityf-project-raises-stakesfor-positive-energy-city-transformation

[22] European Commission. (2020e). Horizon 2020 RUGGEDISED Project 415394. Retrieved from CORDIS DATABASE website: https://cordis.europa.eu/article/id/415394-glasgow-pushes-on-withimplementation-of-smart-and-sustainable-solutions-in-european-project

[23] European Commission. (2020f). Horizon 2020 SPARCS Project Nr. 864242. Retrieved from CORDIS DATABASE website: https://cordis.europa.eu/project/id/864242

[24] European Commission. (2020g). Horizon 2020 STARDUST Project Nr. 774094. Retrieved from CORDIS DATABASE website: https://cordis.europa.eu/project/id/774094 
[25] European Commission. (2020h). Horizon 2020 TRINAGULUM Project Nr. 646578. CORDIS DATABASE, 1-8. Retrieved from https://cordis.europa.eu/project/id/646578

[26] European Commission. (2020i). Smart Cities Marketplace. Retrieved October 10, 2020, from Website website: https://eu-smartcities.eu/

[27] European Commission. (2020j). The Economic Impact of Open Data Opportunities for value creation in Europe. https://doi.org/10.2830/63132

[28] European Commission. (2021). CORDIS. Retrieved May 13, 2021, from Website website: https://cordis.europa.eu/en

[29] Giffinger, R. ;, Fertner, C. ;, Kramar, H. ;, Kalasek, R. ;, Pichler-Milanovic, N. ;, \& Meijers. (2007). Smart Cities: Ranking of European Medium-Sized Cities. Centre of Regional Science (SRF), Vienna University of Technology.

[30] Gil-Garcia, J. R., Pardo, T. A., \& Nam, T. (2015). What makes a city smart? Identifying core components and proposing an integrative and comprehensive conceptualization. Information Polity, 20(1), 61-87. https://doi.org/10.3233/IP-150354

[31] Henderson, J. V. (2010). Cities and development. Journal of Regional Science, 50(1), 515-540. https://doi.org/10.1111/j.1467-9787.2009.00636.x

[32] Ismagilova, E., Hughes, L., Dwivedi, Y. K., \& Raman, K. R. (2019, August 1). Smart cities: Advances in research-An information systems perspective. International Journal of Information Management, Vol. 47, pp. 88-100. https://doi.org/10.1016/j.ijinfomgt.2019.01.004

[33] Kuckartz, U. (2016). Qualitative Inhaltsanalyse. Methoden, Praxis, Computerunterstützung (3., überar). Weinheim Basel: Beltz Juventa.

[34] Lazaroiu, G. C., \& Roscia, M. (2012). Definition methodology for the smart cities model. Energy, 47(1), 326-332. https://doi.org/10.1016/j.energy.2012.09.028

[35] Lyons, G., Mokhtarian, P., Dijst, M., \& Böcker, L. (2018). The dynamics of urban metabolism in the face of digitalization and changing lifestyles: Understanding and influencing our cities. Resources, Conservation and Recycling, 132, 246-257. https://doi.org/10.1016/j.resconrec.2017.07.032

[36] Mayring, P. (2010). Qualitative Inhaltsanalyse. Grundlagen und Techniken (12. Auflag). Beltz.

[37] Molinillo, S., Anaya-Sánchez, R., Morrison, A. M., \& Coca-Stefaniak, J. A. (2019). Smart city communication via social media: Analysing residents' and visitors' engagement. Cities, 94, 247-255. https://doi.org/10.1016/j.cities.2019.06.003

[38] Moustaka, V., Vakali, A., \& Anthopoulos, L. G. (2019, January 1). A systematic review for smart city data analytics. ACM Computing Surveys, Vol. 51, pp. 141. https://doi.org/10.1145/3239566

[39] Odendaal, N. (2003). Information and communication technology and local governance: Understanding the difference between cities in developed and 
emerging economies. Computers, Environment and Urban Systems, 27(6), 585-607. https://doi.org/10.1016/S0198-9715(03)00016-4

[40] Okhrimenko, Sovik, P. \& L. (2019). Digital transformation of the socioeconomic system: prospects for digitalization in society. Revista ESPACIOS, Vol.40(38).

[41] Paola, D. R., \& Rosenthal-Sabroux, C. (2014). Smart City How to Create Public and Economic Value with High Technology in Urban Space. Smart City How to Create Public and Economic Value with High Technology in Urban Space, (June 2014), VIII, 238. https://doi.org/10.1007/978-3-319-06160-3

[42] Parviainen, P., Tihinen, M., Kääriäinen, J., \& Teppola, S. (2017). Tackling the digitalization challenge: how to benefit from digitalization in practice. International Journal of Information Systems and Project Management, 5(1), 63-77. https://doi.org/10.12821/ijispm050104

[43] Ruhlandt, R. W. S. (2018). The governance of smart cities: A systematic literature review. Cities, 81, 1-23. https://doi.org/https://doi.org/10.1080/10630732.2011.601117

[44] Shen, L., Peng, Y., Zhang, X., \& Wu, Y. (2012). An alternative model for evaluating sustainable urbanization. Cities, 29(1), 32-39. https://doi.org/10.1016/j.cities.2011.06.008

[45] Townsend, A. (2017). Smart Cities Book Summary. Futures Group Presentations. https://doi.org/10.7256/2313-0539.2014.3.12545

[46] United Nations. (2019). World Urbanization Prospects 2018 Highlights. Retrieved from www.unpopulation.org.

[47] Wang, H., He, Q., Liu, X., Zhuang, Y., \& Hong, S. (2012, March 15). Global urbanization research from 1991 to 2009: A systematic research review. Landscape and Urban Planning, Vol. 104, pp. 299-309. https://doi.org/10.1016/j.landurbplan.2011.11.006

[48] Washburn, D., Sindhu, U., Balaouras, S., Dines, R., Hayes, N., \& Nelson, L. (2010). Helping CIOs understand "smart city" initiatives. In Forrester Research. Cambridge.

[49] Webster, J., \& Watson, R. T. (2002). Analyzing the past to prepare for the future : Writing a literature review Reproduced with permission of the copyright owner . Further reproduction prohibited without permission. MIS Quarterly, 26(2), xiii-xxiii. https://doi.org/10.2307/4132319

[50] Wirsbinna, A. (2020). PEFnet 2020 - European Scientific Conference of Doctoral Students: Evaluation of Economic Benefits of Smart City Initiative. S .221 (1st, 2020th ed.; H. V. David Hampel, Ed.). Brno: Mendel University in Brno, Zemědělská 1, 61300 Brno.

[51] Wirsbinna, A. (2021). Evaluation of Economic Benefits of Smart City Initiatives. SCENTIA International Economic Review, 1(1), 32-42. https://doi.org/10.52514/sier.v1i1.4 
[52] Zheng, C., Yuan, J., Zhu, L., Zhang, Y., \& Shao, Q. (2020). From digital to sustainable: A scientometric review of smart city literature between 1990 and 2019. Journal of Cleaner Production, 258.

https://doi.org/10.1016/j.jclepro.2020.120689 